\title{
APLIKASI PELABELAN BUKU DENGAN DECIMAL DEWEY CLASSIFICATION (DDC) PADA PERPUSTAKAAN TEKNIK INFORMATIKA UNIVERSITAS PALANGKA RAYA BERBASIS WEBSITE
}

\author{
Deddy Ronaldo ${ }^{\mathrm{a}, 1, *}$, Aderay Saputra ${ }^{\mathrm{b}, 2}$ \\ ${ }^{a}$ Universitas Palangka Raya, Jl. H. Timang \\ ${ }^{\mathrm{b}}$ Universitas Palangka Raya, Jl. H. Timang \\ 1 deddy.ronaldo@gmail.com *; 2 aderay102@gmail.com \\ * corresponding author
}

\section{ARTICLE INFO}

Keywords

Library

Decimal Dewey Classification PHP

\section{ABSTRACT}

The library is a building that contains a collection of books and other archives in physical form neatly arranged in the building room, easy to find and use when needed by the reader.

DDC (Decimal Dewey Classification) is the most widely used classification system in the world. DDC is used to manage and provide access to a collection of books in the library. The DDC is divided into ten main classes, which together cover the entire world of knowledge. Consisting of ten main classes, one hundred divisions, and one thousand parts.

Various problems found in the system are still manual, for example labeling and categorizing books that are not suitable, therefore the authors chose this title to be appointed in the Practical Work College proposal because the author wanted to improve the library work system, especially the Informatics Engineering Library of Palangkarava University. This application aims to improve the efficiency of library work. This library application was built using the PHP language (Hypertext Prepocessor). Dengan didukung oleh perangkat lunak seperti Net Beans, Photoshop dan XAMPP.

\section{Pendahuluan}

Perpustakaan adalah institusi yang mengumpulkan pengetahuan tercetak dan terekam, mengelolanya dengan cara khusus guna memenuhi kebutuhan intelektualitas para penggunanya melalui beragam cara interaksi pengetahuan. Perpustakaan berkembang pesat dan dinamis, saat ini sistem manualnya dirasakan kurang memadai untuk penanganan beban kerja. Keadaan demikian menuntut penggunaan sistem informasi berbasis teknologi telekomunikasi yang merupakan suatu hal yang tidak dapat dihindari di era globalisasi seperti sekarang ini.

DDC (Decimal Dewey Classification) adalah sistem klasifikasi yang paling banyak digunakan di dunia. DDC digunakan untuk mengatur dan menyediakan akses ke koleksi bukubuku yang ada pada perpustakaan. DDC dibagi menjadi sepuluh kelas utama, yang bersamasama mencakup seluruh dunia pengetahuan. Terdiri dari sepuluh kelas utama, seratus divisi, dan seribu bagian.

Berbagai masalah ditemukan dalam sistem masih manual, misalnya pelabelan dan pengkategorian buku yang tidak sesuai, maka dari itu penulis memilih judul ini untuk diangkat dalam proposal kuliah Kerja Praktik dikarenakan penulis ingin memperbaiki sistem kerja perpustakaan, khususnya perpustakaan Teknik Informatika Universitas Palangkaraya. Aplikasi ini bertujuan untuk meningkatkan efisiensi kerja perpustakaan. Aplikasi perpustakaan ini dibangun dengan menggunakan bahasa PHP (Hypertext Prepocessor). 


\subsection{Landasan Teori \\ Pengertian DDC}

DDC (Dewey Decimal Classification) sistem adalah alat organisasi pengetahuan umum yang terus direvisi untuk mengikuti dengan pengetahuan. Sistem ini disusun oleh Melvil Dewey pada tahun 1873 dan pertama kali diterbitkan pada tahun 1876. DDC ini diterbitkan oleh OCLC Perpustakaan Pusat Komputer Online, Inc OCLC memiliki semua hak cipta dalam Klasifikasi Desimal Dewey, dan lisensi sistem untuk berbagai penggunaan.

DDC mencakup keseluruhan ilmu pengetahuan yang dibuat dalam susunan yang sistematis dan teratur. Pembagian ilmu penetahuan dimulai dari koleksi utama yang masingmasing dirinci lagi menjadi bagian-bagian yang lebih kecil, yakni menjadi suatu urutan yang logis dan biasanya dimulai dari yang bersifat umum ke yang bersifat khusus. Dengan demikian, DDC terdiri atas kelas utama, devisi, seleksi, dan subseleksi yang dirinci lagi secara lebih detail.

Sebagai salah satu sistem klasifikasi, DDC harus memiliki unsur-unsur tertentu yang merupakan persyaratan bagi sistem klasifikasi yang baik. Unsur-unsur tesebut yaitu :

1. Sistematika, pembagian ilmu pengetahuan yang dituangkan ke dalam suatu bagan yang lengkap dan dilandaskan pada beberapa prinsip tertentu.

2. Notasi, yang terdiri dari serangkaian simbol berupa angka, yang mewakili serangkaian istilah (yang mencerminkan subjek tertentu) yang terdapat dalam bagan.

3. Indeks relative, yang terdiri dari sejumlah tajuk dengan perincian aspek-aspeknya yang disusun secara alfabetis, dan memberikan petunjuk berupa nomor kelas, yang memungkinkan tajuk yang tercantum dalam indeks pada bagan.

4. Tabel pembantu, yang berbentuk serangkaian notasi khusus, yang dipakai untuk menyatakan aspek-aspek tertentu yang selalu terdapat dalam beberapa subjek yang berbeda. Di dalam DDC edisi terakhir terdapat 7 tabel pembantu yaitu :

1) Tabel Subdivisi Standar

2) Tabel Wilayah

3) Tabel Subdivisi Kesastraan

4) Tabel Bahasa

5) Tabel Ras

6) Tabel Bangsa dan Etnis

7) Tabel Bahasa, dan lainya.

5. Pembagian subjek, sistem DDC dibagi dari subjek besar (kelas utama), menjadi kecil (devisi), lalu dibagi menjadi lebih kecil (subdivisi) dan lebih rinci lagi (tabel lengkap).

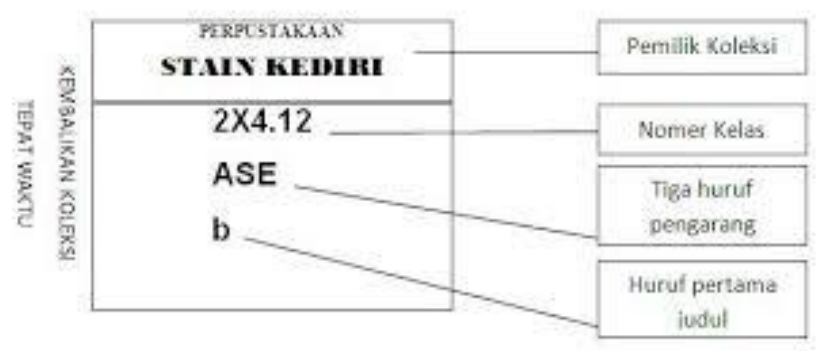

Gambar 3.1. Contoh Format DDC 


\section{Metodologi Penelitian}

\subsection{Metode Pengumpulan Data}

Metode penelitian untuk membuat "Aplikasi Pelabelan Buku dengan Decimal Dewey Classification (DDC) pada Perpustakaan Teknik Informatika Universitas Palangkaraya berbasis Website", yaitu meliputi :

a. Metode pengumpulan data, merupakan tahap pengambilan data atau sampel yang berhubungan dengan permasalahan yang sedang dibahas. Dalam pengumpulan data tersebut menggunakan teknik-teknik pengumpulan data, yaitu Observasi. Observasi merupakan peninjauan langsung ke tempat instansi yang diteliti, yaitu "Jurusan Teknik Informatika Universitas Palangkaraya" sehingga mendapatkan data yang aktual dari hasil penelitian yang dilakukan.

b. Studi kepustakaan, literatur, referensi seperti mempelajari buku dan informasi dari internet yang berhubungan dengan proses pembuatan aplikasi. Melakukan pengamatan terhadap berbagai aplikasi sejenis untuk melengkapi fitur aplikasi ini.

c. Studi konsultasi dan diskusi yaitu berupa tanya jawab dengan dosen pembimbing ataupun orang-orang yang berpengalaman dalam pembuatan aplikasi.

d. Studi praktek dan perancangan yaitu menerapkan teori yang telah diperoleh dari literatur dan konsultasi dengan mempraktekannya yaitu dengan membangun aplikasi desktop yang telah direncanakan.

e. Pengujian dan analisa sistem yaitu untuk mengetahui kesalahan yang terjadi pada tahap perancangan dan juga dilakukan analisa untuk melakukan perbaikan dan pengembangan untuk bisa mendekati kemampuan aplikasi untuk mengklasifikasi buku sesuai dengan yang diharapkan.

\subsection{Metode Pengembangan Perangkat Lunak}

Metode pengembangan dan pembuatan website yang digunakan adalah metode Web2000 (W2000). Merupakan pendekatan yang juga meluaskan notasi UML untuk elemenelemen model.

Web2000 yang digunakan penulis memiliki tahapan-tahapan seperti yang ditunjukkan pada gambar 2.1.

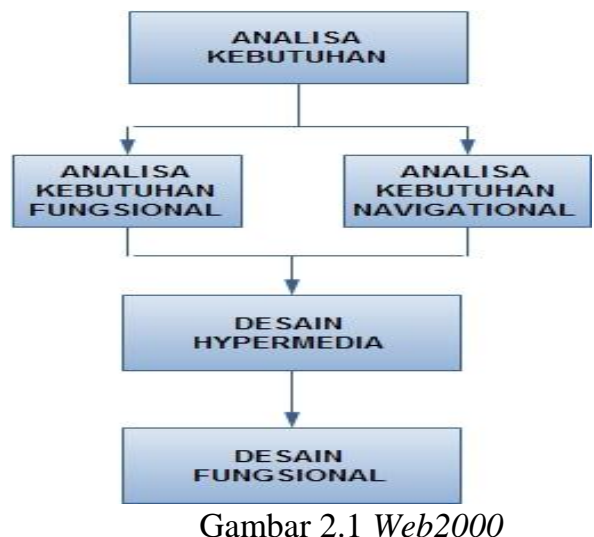

Proses pengembangan dari W2000 dibagi menjadi 3 fase yaitu :

1. Analisis kebutuhan

a. Analisa Kebutuhan Fungsional

+ Definisi Use case, Use Case 
b. Analisa Kebutuhan Navigational +Activity Diagram, Sequence Diagram

2. Desain Hypermedia

+ Sitemap \& Storyboard

3. Desain Fungsional

+ Database

+ Class Diagram

\section{Hasil dan Pembahasan}

3.1 Perancangan

1. Analisis kebutuhan

a. Analisa Kebutuhan Fungsional

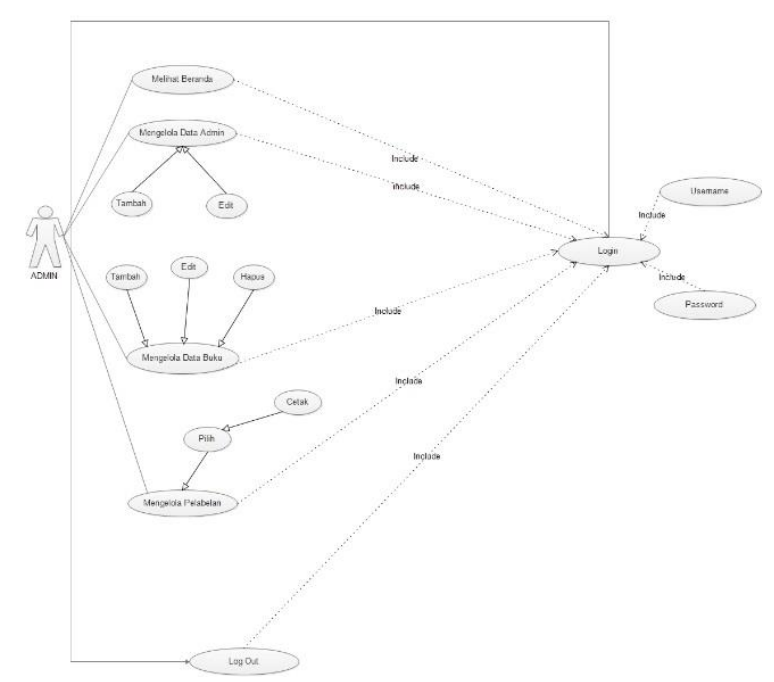

Gambar 4.1. Diagram Usecase

2. Desain Hypermedia

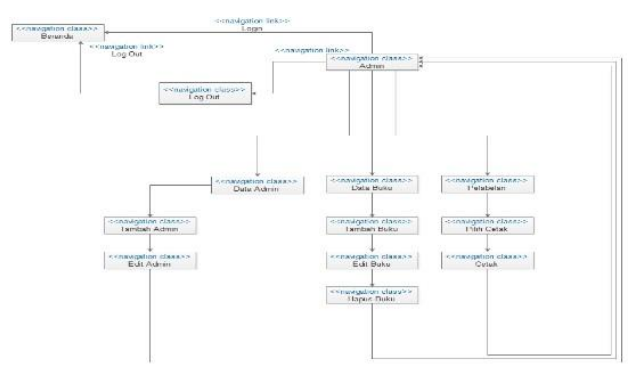

Gambar 4.2. Desain Navigational 
3. Desain Fungsional

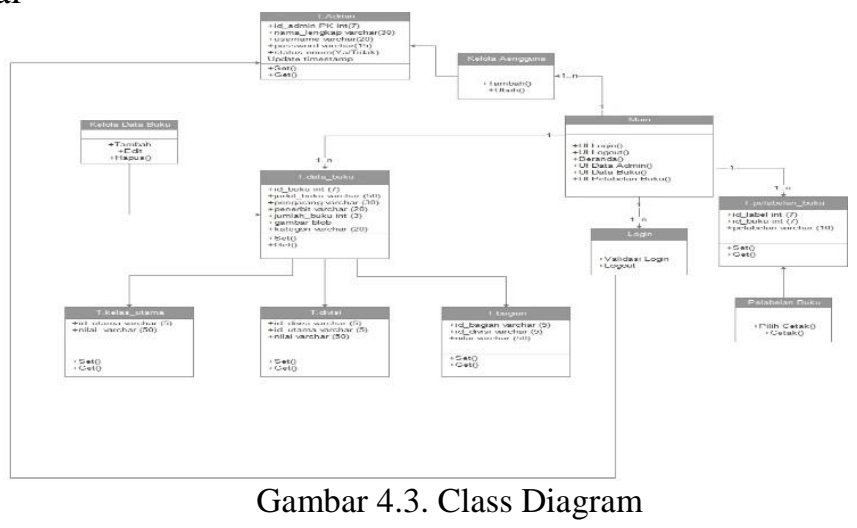

\subsection{Implementasi}

Implementasi Header "Aplikasi Pelabelan Buku Dengan Decimal Dewey Classfication (DDC) Pada Jurusan Teknik Informatika Universitas Palangkaraya Berbasis Website" dapat terlihat pada gambar 5.1 berikut ini.

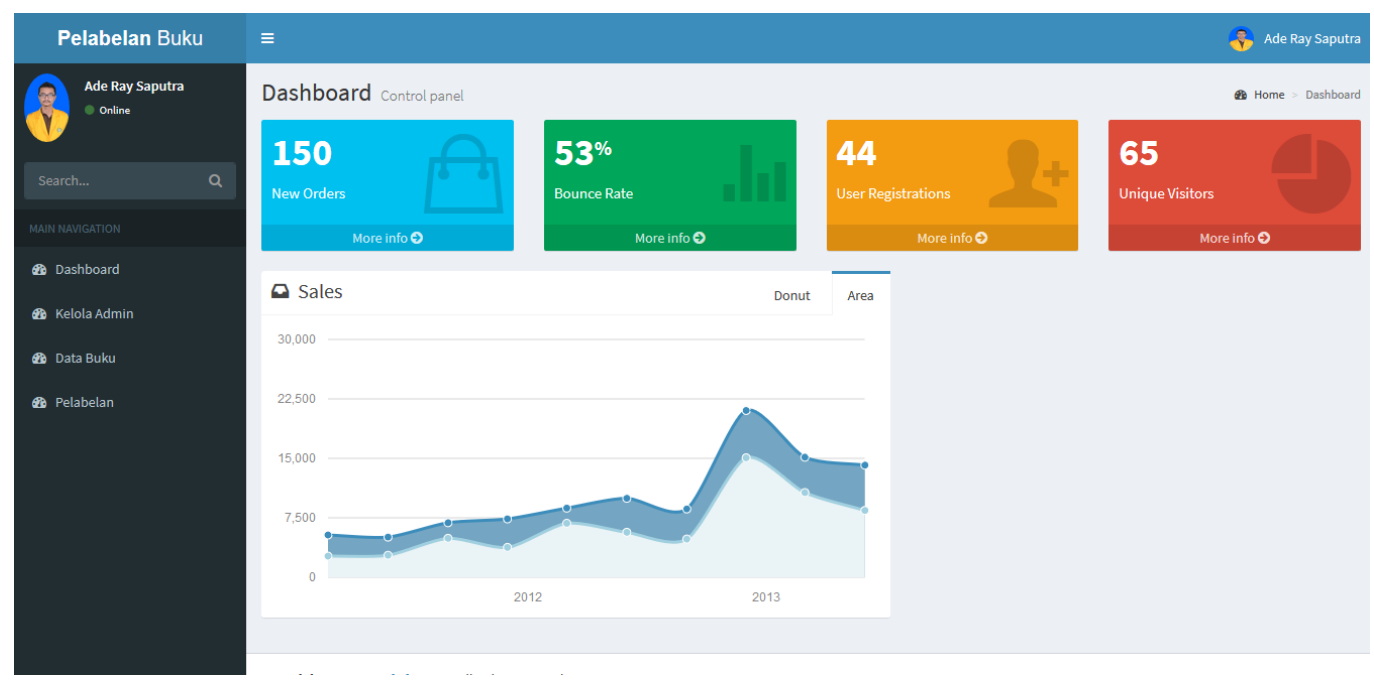

Gambar 5.1 Tampilan Pengunjung Website 


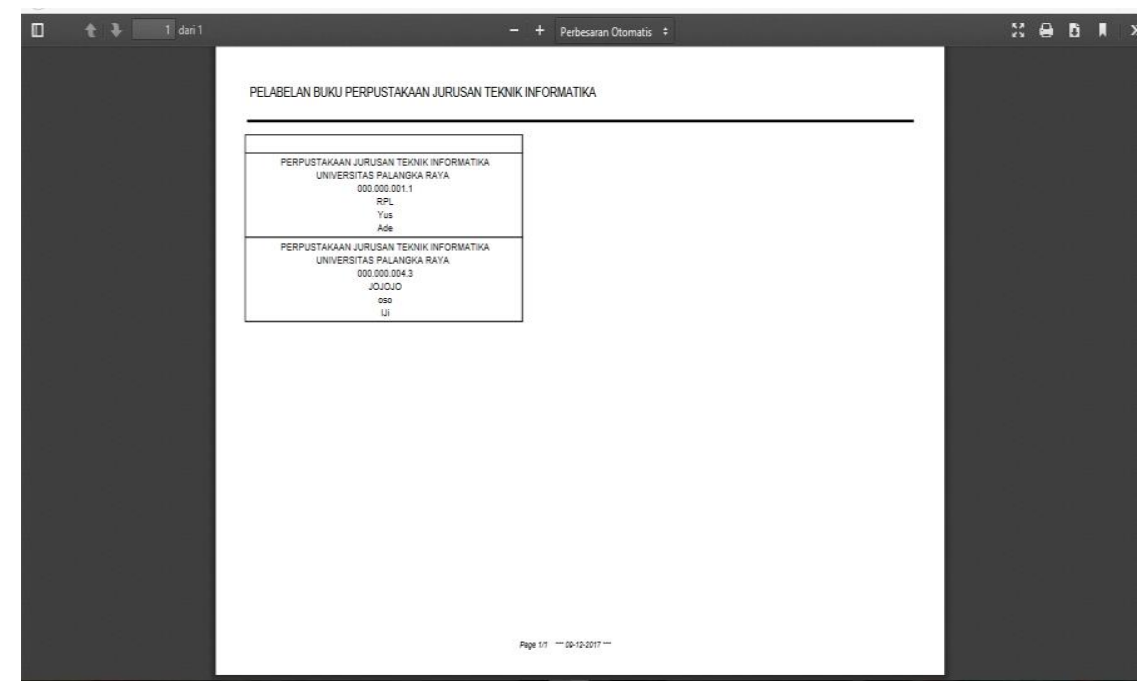

Gambar 5.2 Cetak Pelabelan Berdasarkan judul yang dipilih

Penjelasan Label Yang Dihasilkan

Pelabelan yang digunakan dalam Aplikasi Pelabelan Buku Berbasis Website ini terdiri dari Kode Label, Judul Buku, Pengarang Buku, dan Penerbit Buku. Berikut Penjelasannya

Kode Label : Kode Label dihasilkan dari 3 digit kelas utama, 3 digit divisi, 3 digit bagian, dan nomor urut buku yang telah di inputkan ke dalam Aplikasi.

Judul Buku : Judul Buku dihasilkan dari data buku yang telah di input ke dalam Aplikasi.

Pengarang : Kode Pengarang diambil dari 3 digit nama depan Pengarang Buku dari data buku yang telah di inputkan.

Penerbit : Kode Penerbit diambil dari 3 digit nama depan Pengarang Buku dari data buku yang telah di inputkan.

PELABELAN BUKU PERPUSTAKAAN JURUSAN TEKNIK INFORMATIKA

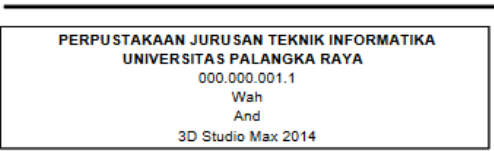

Gambar 5.3 Label Buku yang dihasilkan

\section{Kesimpulan}

\subsection{Kesimpulan}

Dari program aplikasi yang telah dibuat dengan judul "Aplikasi Pelabelan Buku Dengan Decimal Dewey Classification (DDC) Pada Jurusan Teknik Informatika Universitas Palangkaraya" maka dapat disumpulkan bahwa :

Dalam merancang dan membangun "Aplikasi Pelabelan Buku Dengan Decimal Dewey Classification (DDC) Pada Jurusan Teknik Informatika Universitas Palangkaraya" yang dapat digunakan oleh admin, maka digunakanlah metode pengembangan sistem perangkat lunak W2000 dengan tahapan yaitu Analisi Kebutuhan, yang terdiri dari Fungsional dan Navigational. Desain Hypermedia, yang terdiri dari Sitemap \& StoryBoard. Desain Fungsional, 
yang terdiri dari Database \& Class Diagram. Pada tahap pembuatan diperlukan software penunjang seperti software pemrograman web dan sistem database, dimana untuk mendesain tampilan web diperlukan Photoshop CS6 untuk mendesain dan manajemen database menggunakan MySQL, serta membangun webnya menggunakan bahasa pemrograman $P H P$, HTML, CSS, CMS dan Java Script. Website ini secara umum mempergunakan proses pengolahan manajemen database yaitu menambah data, mengubah data dan menghapus data yang dalam penggunaannya dari sisi admin berupa manajemen kelola data admin, kelola data buku, dan kelola pelabelan buku.

\subsection{Saran}

Berikut adalah saran-saran untuk pengembangan lebih lanjut terhadap aplikasi pelabelan buku ini :

1. Untuk Pengembangan lebih lanjut aplikasi ini diharapkan dapat dikembangkan lagi desain dari website ini.

2. Pada kesempatan mendatang diharapkan dapat menambah kategori klasifikasi yang telah dibuat. Karena DDC selalu mengeluarkan versi terbaru.

\section{DAFTAR PUSTAKA}

[1] Sugiyama. 2017. UML CLASS DIAGRAM. [Online]. Situs : http://link.springer.com/chapter/10.1007\%2F3-540-63938-1_86 [Di akses pada tanggal 30 Oktober 2017. Pukul 19.00 WIB.]

[2] Tim Penyusun Satckoverflow. 2017. UML ON MICROSOFT VISIO. [Online]. Situs : 7 [Di akses pada tanggal 30 Oktober 2017. Pukul 19.30 WIB.]

[3] Tim Wiki. 2017. WEB DEVELOPMENT. [Online]. Situs : http://wikipedia.org [Di akses pada tanggal 30 Oktober 2017. Pukul 15.05 WIB.]

[4] Tim Wiki. 2017. PERPUSTAKAAN. [Online]. Situs : https://id.wikipedia.org/wiki/Perpustakaan. [Di akses pada tanggal 1 November 2017. Pukul 15.05 WIB.]

[5] Tim Software Testing. 2017. Blackbox Testing. [Online]. Situs : http://www.softwaretestinghelp.com/black-box-testing/ [Di akses pada tanggal 2 November 2017. Pukul 15.05 WIB.]

[6] Tim OCLC 2017. Decimal Dewey Classification [Online]. Situs : https://www.oclc.org/en/dewey.html [ Di akses pada tanggal 3 November 2017. Pukul 19.00 WIB.] 